\title{
Analysis on the Ways to Improve Thesis Writing Ability of Postgraduates in Design Direction of Product Design
}

\author{
Qingwen Dong \\ Jiangxi Normal University, Nanchang City 330022, Jiangxi Province
}

\begin{abstract}
The ability of having a high level of thesis writing ability is crucial to being a graduate student. Therefore, this article takes postgraduates of product design direction of design science as an example, analyzes the training programs of the discipline at the undergraduate and graduate levels, and summarizes two major ways for graduate students in this discipline to improve their thesis writing ability. One is active learning and diligent practice, and the other is good at thinking and outputting thesis. Specific implementation methods are provided for each approach, aiming to resolve doubts in academic writing for graduate students of the discipline, analyze the corresponding reasons and provide corresponding solutions.
\end{abstract}

Keywords: Design; Product Design; Postgraduate; Thesis Writing

The most important thing for students in the graduate stage is to write high-quality papers. It is very important to have a highlevel paper writing ability. It will not only affect their scientific research ability, but also affect whether they can write an excellent graduation thesis and graduate successfully. And through the thesis can also reflect the knowledge level and comprehensive quality of the graduate student, because the thesis is the best embodiment of the author's thoughts, level and ability. This article analyzes the training program of postgraduates of product design direction of design science and summarizes the ways to improve the ability of graduate students in this discipline. It aims to solve the doubts, analyze the reasons and provide corresponding solutions for the academic writing of graduate students in this discipline.

\section{Active learning and diligent practice}

Although postgraduates of product design direction of design science have already possessed the corresponding product design knowledge reserve during the undergraduate period, it does not mean that the knowledge of product design discipline can be built up a complete theoretical framework at the graduate level. Since most undergraduates in the product design discipline in China pay more attention to design practice, they emphasize the study of computer software and the output of design plans, and lack the guidance of theory and writing. The external cause cannot be changed by the individual ability of graduate students, but the internal cause can be improved by oneself. How to do active learning and diligent practice Here are some methods.

\subsection{Build a complete basic knowledge framework}

Although they have basic knowledge, they lack a theoretical knowledge structure. According to the survey, the basic knowledge received by product design graduate students during the undergraduate period is mainly related to industrial design history, design methodology, design psychology and other related knowledge. It can be seen that objectively speaking, there is a lack of a macro-level knowledge structure of design for graduate students, such as the history of world design. Therefore, design graduates in product design should quickly build a complete basic knowledge framework at the graduate level based on their lack of knowledge. This is also the most basic and most critical step for doing academic research and writing academic thesis.

\subsection{Understand the frontiers of the subject and participate in academic lectures}

As a postgraduate of product design direction of design science, you must always understand the frontier of the subject. Because the nature of the product design discipline determines the importance of understanding the frontiers, if you stay in your own world and do not keep pace with the times, then the papers written are undoubtedly lack of innovation and no breakthrough. How to understand the frontiers of disciplines can be achieved by participating in academic lectures, which generally discuss the frontiers of design and hot topics. Therefore, attending more academic lectures can expand the academic exchange group for graduate students on the one hand, and also enrich the knowledge reserve and expand the knowledge structure on the other hand. Keep abreast of national development trends and subject hotspot trends. It provides reference directions and research ideas for thesis writing. 


\subsection{Interdisciplinary and interdisciplinary sustainable development}

As we all know, product design is an interdisciplinary subject. It has crossed the direction of economics, sociology, psychology and other disciplines, so by understanding the knowledge and information of other related disciplines. On the one hand, you can expand your research scope, and you can learn from other disciplines to do academic research from the perspective of product design, which is very conducive to cultivating graduate students' innovative awareness and ability. It is precisely because of the society's requirements for product design talents that interdisciplinary and interdisciplinary learning is necessary at the graduate level. Whether in a design company or in a university, you will be exposed to talents in different fields. Only when you have a good foundation at the graduate level can you be able to carry out scientific research in the future. This can improve their own development opportunities and expand their horizons.

\subsection{Combination of theory and product design practice}

As an academic product design graduate student, after having a complete basic knowledge structure, understanding the frontiers of the discipline, and having interdisciplinary knowledge, he also needs to test the knowledge he has learned through design practice. Design practice is a very critical step. It is a springboard for turning theory into practice. All theories are for practice. Design practice here refers to going to enterprises and design companies to participate in design, and field inspections to output design plans. This is conducive to internalizing the learned knowledge, which internalizes in the heart, externalization and shape. Test the knowledge learned through design practice, and constantly look for knowledge loopholes on the basis of practice, and make up for deficiencies in time.

The four methods mentioned above are not independent of each other, but are interrelated, interlinked and complementary. After having the above-mentioned abilities, how to start when writing a thesis. Specific approaches and methods are also mentioned below.

\section{Good at thinking and outputting papers}

After the accumulation of the above-mentioned basic knowledge, it is necessary to talk about specific thesis writing methods. Of course, there are various methods, and graduate students should choose their own method according to their actual situation and ability after studying methods. So learning to write papers is an indispensable ability for graduate students. What is a paper, what should be paid attention to when writing a paper, what kind of paper is a good paper, and how to write a good paper, I will talk about them one by one below.

\subsection{Understand the basic writing requirements paradigm}

When writing a paper, pay attention to the basic format of the paper, such as title, abstract, keywords, etc. So you can think about the purpose of my thesis before writing the paper. Thinking about the purpose of my paper and where I am going to publish it in advance can make writing a paper more effective. Of course, a good topic selection also determines whether the results of the thesis have been achieved. Whether a good topic selection can be selected is also based on the above mentioned factors such as whether they have solid basic skills and other factors. many times in the process of writing, we slowly discover better topics. The topic selection does not mean that the topic will not be changed after the topic is set. It will be written down according to the topic, even though the topic is found to be wrong later. Rather, you select a research target and continue to study along the target, and you will be able to discover the uniqueness of the target, and discover innovative points on the basis of a large amount of knowledge.

\subsection{Formulate a complete thesis plan and goals}

After talking about the above content, I will talk about how to write a good paper. You must set a strict thesis plan and goals for yourself. If there is no goal, then everything you do will be universal, so you must set yourself a research goal. For example, how long does it take to write a paper, analyze and modify the length of the paper to collect data, analyze and summarize the length of the data, and write and modify the time to make a comprehensive plan. So making a good thesis plan and goal is the first step in starting to write a thesis, and it determines whether your paper is exquisite.

\subsection{Maintain the rhythm of daily reading and writing}

Formulate a complete thesis plan and goals, and then implement it. The best way is to keep the rhythm of reading and writing every day. Don't give up halfway. Once you give up, it is difficult to pick it up. Keep for at least half an hour every day to read superior papers, analyze papers, and write down your own ideas. When writing, excerpt excellent expressions and sentences, and gradually transform the summarized knowledge into one's own knowledge. In the beginning, you can imitate. Imitation is the best teacher. Of course, the object of imitation is also an excellent paper. How to choose an excellent paper to imitate is generally to choose an article published by the author or institution that is the most authoritative in the topic. The subject of writing can start from the literature review. There is a large amount of literature accumulation and the construction of a method system, so that it will not panic later.

\subsection{Actively participate in discussions and modify and improve in time}

After writing the paper, it is not over yet, so you must actively participate in the discussion and revise and improve the paper in time. You can show the thesis to your supervisor or other teachers and other graduate students for examination. Because it is difficult to find problems with the papers written by yourself, after you show them to others, they will evaluate your papers from an objective perspective. In particular, teachers and people who have more knowledge than you and have strong essay writing skills can give you instructive advice. After the paper is submitted, the editor will also give corresponding suggestions. The author must have the ability to face these criticisms and suggestions. Good papers are revised and handed over to experts for review is essential to improve the research ability of graduate students. 


\section{Conclusion}

The specific methods mentioned in this article still need to be used by graduate students consciously. Although many colleges and universities have also opened courses to improve their writing ability for postgraduates of product design direction of design science, they still need to improve their own quality. Otherwise, everything can only be on paper. Of course, don't write papers for the sake of publishing papers. This will not improve fundamentally. You just do it for the sake of doing it. Interest is the best teacher. Don't be impatient in the process of writing. It's impossible to write every paper of high quality. Writing requires time and quantity. Only with the accumulation of quantity can it lead to qualitative changes. So persistence is victory. In fact, the fundamental problem is that postgraduates' learning awareness needs to be improved, and then the methods can be integrated to eventually cultivate postgraduates with high-level thesis writing skills.

\section{References}

1 Cheng Yizhen. Analysis of common problems in design master's thesis writing [J]. Fujian Tea, 2020, 42(01): 191.

2 Duan Li. Research on the Cultivation of Postgraduate Research Ability [D]. Hunan University, 2003.

3 Hu Linglin. Research on the Cultivation Mode of Graduate Students in my country's Universities [D]. East China Normal University, 2004.

4 Liang Huixing. On the Writing Methods of Degree Thesis [J]. Private Law, 2005, 9(01): 400-454.

5 Liu Runjin, Li Min, Yuan Yongbin. Several Ways to Cultivate the Research Ability of Graduate Students [J]. Degree and Graduate Education, 2004(11): 38-41.

6 Liu Ziyun. Innovative research on the training model of academic postgraduates [D]. Guangxi University for Nationalities, 2012.

Ni Jizhen. Research on the Influence of Dissertation Writing on Graduate Students' Innovative Ability [D]. Central China Normal University, 2010.

7 Tang Jichuan, Wang Junlu. Analysis of the integrated writing method of design master's thesis and graduation design [J]. Beauty and Times (Part 1), 2018(02): 113-115.

8 Wang Jian, Sun Lin. Based on literature review to improve the writing level of graduate students' thesis [J]. Chinese Journal of Immunology, 2017, 33(5): 759-762.

9 Wang Yanni. Research on Teachers' Cultivation of Postgraduate Research Ability [D]. Hunan University, 2005. 